\title{
Determining middle school students' perceptions of the concept of artificial intelligence: A metaphor analysis
}

\author{
Kadir Demir ${ }^{*}$ \\ Department of Computer Education and Instructional Technology, Dokuz Eylul University, \\ İzmir, Turkey \\ ORCID: 0000-0001-9568-9450
}

\section{Gür Emre Güraksin \\ Department of Computer Engineering, Afyon Kocatepe University, Afyonkarahisar, Turkey ORCID: 0000-0002-1935-278}

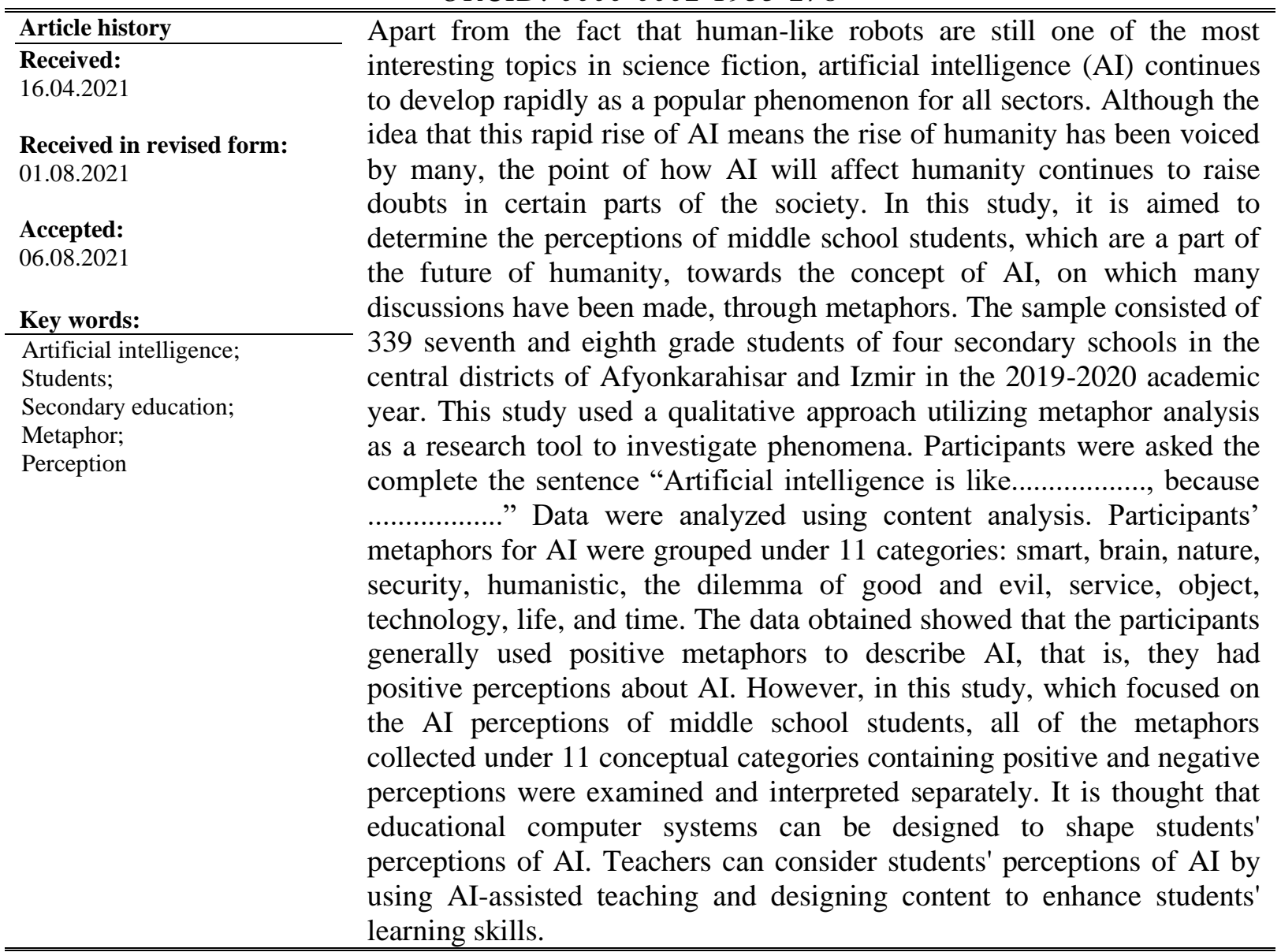

\footnotetext{
*Correspondency: kadir.demir@deu.edu.tr
} 


\section{Introduction}

Information processing technologies had been initially developed for numerical computing. However, they have undergone a geometric increase in capacity and have been capable of processing data that is too complex for the human brain. Today, information processing technologies, as well as multimedia elements (digital data, sound, text, video, and animation), the Internet, and mobile and wearable technologies, are an integral part of the world, making our lives better and us more productive. Internet of Things (IoT), Industry 4.0, and Artificial Intelligence (AI) have dramatically changed the way we communicate and work.

In 1955, John McCarthy (Dartmouth College, the United States) coined the term Artificial Intelligence (AI) in a proposal for the 1956 Dartmouth Summer Research Project (Clarke, 2019). In the proposal, AI was based on the assumption that "every aspect of learning or any other feature of intelligence can in principle be so precisely described that a machine can be made to simulate it" (McCarthy et al., 2006). In the broadest sense, AI is defined as information processing models developed to perform tasks initially performed by humans (Skilton \& Hovsepian, 2017) or as the totality of algorithms and computer software systems used to perform processes that require cognition (Cross \& Lucas, 2019). The World Bank (2018) defines it as computer systems collecting, analyzing, and processing big data in real time and ultimately recognizing patterns, making decisions, and learning from data and experience.

Dickson (2017) presents AI in three basic categories: Artificial Narrow Intelligence (ANI), Artificial General Intelligence (AGI), and Artificial Super Intelligence (ASI). ANI performs tasks efficiently (playing chess or Go, making purchase recommendations, or forecasting sales or weather). AGI performs like humans or as well as humans. It seems very difficult for current computers to reach that level, but it is predicted that AGI will have been developed by the end of this century. ASI is a type of AI that outsmarts even the most intelligent human in scientific creativity, general wisdom, and social skills. It is argued that ASI may be a threat or a blessing for humanity (Bostrom, 2003; Cellan-Jones, 2014).

AI, which was initially a part of computer science, has become a promising technology for solving problems in many areas. It has been integrated into numerous products and has become a significant part of modern life. Therefore, it is one of the current hot topics in the literature today. Advances in AI technology have led many to voice their concerns on the possibility of super-smart machines, making safety and ethical issues even more pressing. There has been a growing body of research and discussion on the safety and moral status of thinking machines (Bostrom \& Yudkowsky, 2014; Köse, 2018; Dubhashi \& Lappin, 2017). Given all advances and debates, AI technology will be a critical topic for future generations as well.

The scientific purpose of AI is to create computer programs that can make symbolic inferences or display logical behaviors to understand intelligence (Singh, Mishra \& Sagar, 2013). AI is used in the fields of transportation (Bösch et al., 2018), health (Sitterdinget al., 2019), agriculture (Elahi et al., 2019), production (Gelmereanu et al., 2014), and banking (Tavana et al., 2018). It has also started to come into play in education with teaching robots, and intelligent tutoring and adaptive learning systems (Chassignol et al., 2018).

AI is an umbrella term encompassing numerous subdisciplines and methods, such as neural networks, machine learning, voice, image, text recognition, and robotics. Machine learning is 
the use of computer systems to recognize patterns and make predictions. Deep learning is a subdiscipline of machine learning. Deep learning is learning from big data through deep artificial neural networks based on complex algorithms (Touger, 2018).

The ever-increasing amount of digital data and significant advances in AI have significantly impacted the use of automated decision-making processes which can generally be defined as decisions made by technological means without human intervention (Arauja et al., 2020). The increased interest in automated decision making has brought some concerns. Hence, research was conducted on the bias of automated decision-making processes and concerns regarding the use of algorithms in decision-making (Arauja et al., 2020; Hajian et al., 2016).

Rapid developments in the field of AI are of great importance for humanity. AI, which makes rapid progress in many areas, has become a part of our daily lives. The development of AI is particularly strongly supported by the industry. AI systems, which have a cost-reducing effect especially for industry and companies, are taking more and more people's place every day. Although the use of AI contributes to the solution of many of the challenging problems we face, there are many discussions about whether AI can be a great threat to humanity. Such debates against AI threats by many AI researchers and public figures have made the potential AI hazard one of the main topics of public discourse (Nowak et al., 2018). Despite these discussions, AI has become a part of the educational vision in many countries.

AI is often used to develop educational content and intelligent tutoring methods and systems, evaluate students and improve teacher-student interaction (Chassignol et al., 2018).

According to the World Bank Report, three basic skill sets are becoming increasingly important for today's employees: advanced cognitive (complex problem solving), sociobehavioral (teamwork), and adaptable (reasoning and self-efficacy) skills. The World Bank (2018) recommends that countries invest in human resources from early childhood to help people acquire those skills. The transformation in science, technology, and economy makes AI and its subdisciplines all the more critical. Many countries integrate AI in education. China has taken the lead and introduced a nine-chapter textbook (e.g., the history of AI, facial recognition, autonomous driving, and public safety) to 40 high schools as a pilot study (Sinha, 2018). The Chinese Academy of Sciences, Google, and some universities collaborated to develop a textbook series on AI and published it in electronic and print form for kindergarten, and primary, middle, high, and vocational schools (Zinan \& Kai, 2018). Some argue that AI should not be taught to young children before they learn arithmetic, while others state that AI may destroy teacher-student interaction. It would be a mistake to replace social interaction with AI (Chassignol et al., 2018).

There are many studies investigating the perceptions of higher education students towards AI (Sit et al., 2020; Yun et al., 2020; Yüzbaşığlu, 2021). A limited number of studies are found in the literature for studies investigating the perceptions of primary or secondary school students towards AI. The study which implemented with the primary and middle school students (third to sixth grades) claims that learning AI empower students to accomplish emerging societal, technological, and environmental challenges (Chai et al., 2021). Chai et al. (2021) developed a questionnaire to reveal students' perceptions of and behavioral intentions towards learning AI. There is another scale development study which shows that AI literacy was mediated by students' perception of AI relevance (Dai, 2020). In this study, a valid instrument was developed to measure primary school students' readiness to learn about AI. In addition, Kim et al. (2020) implemented study in higher education to investigate students' 
perceptions about AI teaching assistants.

According to the Education Vision 2023 Document presented as a roadmap for education in Turkey, AI becomes increasingly relevant, and machines are about to surpass human learning ability and intelligence (Ministry of National Education, 2019). The Education Vision 2023 Document shows that the Ministry of National Education (MoNE) aims to adopt a data-based management approach and use decision support systems, feedback, online development monitoring systems, big data, and learning analytics at every stage. The MNE plans coding activities to help students develop computing and production skills. We think that this study will be a guide for the MNE to achieve those goals.

It seems inevitable that AI, which is the focus of many discussions, will be a part of our future. In this context, the perception of students, who are the future of humanity, on AI is particularly important. In this study, a metaphor analysis has been conducted on the perspectives and perceptions of students, our future, towards AI. At the same time, it was analyzed how the discussions on AI affected them. This study was carried out in order to fill the gap in the studies on determining the AI perceptions of middle school students in the literature.

\section{Objective of the research and significance}

This study, which emerged and carried out based on research on the evaluation of AI perceptions and prejudices, investigated the attitudes of middle school students towards AI and to what extent the concept of AI affects children. The representative of Turkey's population in this study with the results of a survey carried out in this context were examined as a sample. There is no published research examining secondary school students' perceptions of AI. Therefore, we believe that this study will fill that gap in the literature. Given the global developments, such studies can make primary and secondary students more aware, curious, and interested in AI and pave the way for further research and textbook development on AI.

\section{Statement of the research problems}

It is mentioned that students must be ready for the future of AI-supported education (Luan et al., 2020). Growing interest in big data and machine learning has accelerated the evolution of AI in education. As a result, the widespread use of AI technologies lays the groundwork for transformation in the education system and the learning environment. There is a need to concentrate on AI-supported teaching in order to enhance student learning skills (Song, \& Wang, 2020). In this case, students' perceptions of AI have the potential to influence their acceptance and use in the future where AI-supported education takes place. The point where this research will significantly contribute to the field is to reveal the students' perceptions of the AI. This study sought answers to the following research problems.

(1) What metaphors did secondary school students generate for AI?

(2) Under what conceptual categories did secondary school students' metaphors fall?

\section{Method}

This section addressed the research model and procedure, research context and sample, instrument used and validation, data analysis, credibility, trustworthiness, assumptions, and limitations. 


\section{Research model and procedure}

This study used a qualitative approach utilizing metaphor analysis as a research tool to investigate phenomena (Yıldırım \& Şimşek, 2011). It is a phenomenology approach that reveals the latent causes behind the experiences of individuals (Matua \& Van Der Wal, 2015). Since this study was created by collecting data from different geographical regions and different school types (state-private), the number of samples was kept high (Avidov-Ungar et al., 2020). Qualitative research is based on assumptions regarding ontologically multiple realities. In terms of epistemology, this situation is supported by the differentiation of perceptions and meanings according to culture. This study performed using the qualitative research method which has an interpretivist perspective (Twining et al., 2017). "Artificial intelligence" was the phenomenon in question in this study.

\section{Research context and sample}

\section{Participants}

The population of the study is comprised of the middle school students in Turkey. Participants were recruited using typical case sampling, which is a purposive sampling method. Typical case sampling allows the researcher to develop a profile of what is usual or average for a particular phenomenon (Yıldırım \& Şimşek, 2011). The sample consisted of 339 seventh and eighth grade students (168 female, 171 male) from four secondary schools in the central districts of Afyonkarahisar and Izmir in the 2019-2020 academic year. One school in each province is chosen as a public school and the other as a private school. A rich explanation of the relevant schools and participants should be given at this point, as suggested in the literature (O'Brien et al., 2014; Santiago-Delefosse et al., 2016). The reason why public and private schools were chosen together to constitute the very sample is that private schools in which the study was performed distinguish from public schools with advanced technical equipment, a low number of students per teacher, and a high socio-economic status. Table 1 presents the demographic characteristics of the participants. Before the data collection stage, permission was obtained from the Ministry of National Education for data collection. In addition, the data collection phase started with the ethical approval of the Ethics Committee of Dokuz Eylül University Institute of Educational Sciences. Participants who agreed to participate in the study by informing the parents of the students with informed consent forms during data collection were included in the study.

Table 1. Demographic characteristics

\begin{tabular}{lll}
\hline Variables & & Frequency \\
\hline Gender & Female & 168 \\
& Male & 171 \\
Grade Level & 7 & 173 \\
& 8 & 166 \\
School type & Public & 188 \\
& Private & 141 \\
\hline & Total & 339 \\
\hline
\end{tabular}

\section{Data collection tool}

Metaphor studies use the words "like" and "because" to construct such statements as "X is like .....; because ......" The word "like" is used to determine the relationship between a concept and the respondent forming a simile. The word "because" is used to allow the respondent to describe through a metaphor to explain further why he/she likens that 
concept and make a reasonable explanation about it (Saban, 2008) justifying the preference. The data collection tool was presented to the evaluation of academicians who are experts in the fields of Turkish, Psychology, Instructional Technologies, Measurement and Evaluation, and its validity was ensured by making relevant corrections. A pilot study was performed with 12 middle school students to assess the comprehensibility and appropriateness of the data collection tool by teachers working in both school types. Data were collected using a semistructured survey, including the statement "Artificial intelligence is like....

because ............................," which participants were asked the complete. Participants were asked to focus on the concept of "artificial intelligence" and generate metaphors about it. Demographic information was also collected using the semi-structured survey.

\section{Data analysis}

Data analysis will be carried out within the framework of the study based on inductive reasoning. This technique, which assumes that the collected data is tested in the literature, seeks to achieve general outcomes from specific situations (Twining et al., 2017). The text data on the written papers collected from the participants were transferred to the digital environment by the researchers. The anonymised data were analyzed via NVivo 12 (qualitative data analysis software). Participants' schools are coded separately. Qualitative data were analyzed using content analysis, which is used to conceptualize and organize data, and then to develop themes and interpret them in a way that the reader can comprehend (Yıldırım \& Şimşek, 2011). The metaphors were analyzed in five stages: (1) coding and sifting, (2) compiling a sample metaphor image, (3) developing categories, (4) establishing validity and reliability, and (5) feeding data to a computer for quantitative data analysis (Saban, 2008b).

\section{Coding and sifting}

First, the metaphors were coded using Nvivo 12, and then, a draft metaphor list ( $\mathrm{n}=$ 95) was developed. Twenty-three participants were excluded from analysis because they did not know about AI. Incomplete surveys or those with only metaphors or explanations and metaphors that did not make sense were also sifted from the analysis. All in all, data from 70 participants were not included in the study.

\section{Compiling a sample metaphor image}

The coding and sifting stage resulted in 80 valid metaphors (see Table 2). The metaphor list was sorted in alphabetical order. The metaphors were presented with statements explaining them in order to categorize them quickly and achieve data validity.

Table 2. Participants' metaphors for AI

\begin{tabular}{|c|c|c|c|c|c|c|c|}
\hline No & Metaphor & No & Metaphor & No & Metaphor & No & Metaphor \\
\hline 1 & Tree & 21 & Earth & 41 & Operation System & 61 & Threat \\
\hline 2 & Tree branches & 22 & End of the World & 42 & Employee & 62 & Danger \\
\hline 3 & Mindless & 23 & Apathy & 43 & Good & 63 & Phone \\
\hline 4 & Smart Assistant & 24 & Universe & 44 & Cloning & 64 & Laziness \\
\hline 5 & Smart Human & 25 & Future & 45 & Coding & 65 & Indolence \\
\hline 6 & Clever Entity & 26 & Unnecessary & 46 & Copy & 66 & Space \\
\hline 7 & Elbow Grease & 27 & Nice & 47 & Bad & 67 & Space Shuttle \\
\hline 8 & Lion & 28 & Dough & 48 & Bad & 68 & Virus \\
\hline
\end{tabular}




\begin{tabular}{|c|c|c|c|c|c|c|c|}
\hline 9 & Connectedness & 29 & Sensitivity & 49 & Sandstone & 69 & Artificial \\
\hline 10 & Glass & 30 & Imagination & 50 & Lines of Business & 70 & Creativity \\
\hline 11 & Unique & 31 & $\begin{array}{l}\text { Both Good and } \\
\text { Evil }\end{array}$ & 51 & Excellence & 71 & Helper \\
\hline 12 & $\begin{array}{l}\text { Source } \\
\text { Information }\end{array}$ & 32 & Servant & 52 & Spider Web & 72 & Software \\
\hline 13 & Computer & 33 & Medicine & 53 & Autonomous & 73 & Food \\
\hline 14 & $\begin{array}{l}\text { Information } \\
\text { System }\end{array}$ & 34 & Personality Traits & 54 & Money & 74 & Newborn \\
\hline 15 & Knife & 35 & Beyond Human & 55 & Fingers & 75 & Innovation \\
\hline 16 & Boat & 36 & Human-made & 56 & Picture Chart & 76 & Manager \\
\hline 17 & Discovery & 37 & Like Humans & 57 & Robot & 77 & Harmful \\
\hline 18 & Hardworking & 38 & $\begin{array}{l}\text { Autonomous } \\
\text { Vehicle }\end{array}$ & 58 & Robot Human & 78 & Intelligence \\
\hline 19 & Monster & 39 & Internet & 59 & Weapon & 79 & Intelligent Being \\
\hline 20 & Childhood & 40 & Irresoluteness & 60 & System & 80 & Intelligent Human \\
\hline
\end{tabular}

\section{Developing categories}

The metaphors were examined for their relationship with one another. Each metaphor was analyzed for the topic and source and the relationship between the two. The metaphors were associated with themes, resulting in 11 conceptual categories.

\section{Establishing the trustworthiness of the study}

Qualitative research has different approach to establish validity and reliability. In qualitative research, the trustworthiness has to be ensured via credibility, transferability, dependability and confirmability (Lincoln \& Guba, 1985). Participants were not manipulated in any way. For the credibility and transferability, the metaphors and their sources were directly addressed. Another step of reliability in qualitative research is interrater reliability which also makes stronger credibility. An expert with experience in qualitative research and the topic in question was consulted to achieve interrater reliability. The expert was asked to match the metaphors with the conceptual categories. Interrater reliability equation suggested by Miles and Huberman (1994) was calculated in the study, since it is a frequently preferred coefficient in qualitative education studies (Akay, 2017; Pujilestari et al., 2020; Teksan, 2019). An agreement of $\geq 90 \%$ between the researcher and expert indicates reliability. In this study, the researcher and expert disagreed on three metaphors, resulting in an interrater reliability of $96 \%$. Independent researcher working with the same department with the first author, confirmed that the interpretations were derived from data and that the findings derived from the data were accurate. In this way, dependability and confirmability has been assured. A thorough description of the study context, the characteristics of the participants and their school context, the sampling methods, coding and exclusion, the data collection, the data analysis, and process of the compiling metaphors and categories are presented to ensure transferability.

\section{Feeding data to a computer for quantitative data analysis}

Data were analyzed using the Statistical Package for Social Sciences (SPSS, version 26.0) at a significance level of 0.05 . Descriptive statistics were used for analysis and presented in the "Results" section. 


\section{Assumptions} honestly.

The study assumed that participants answered the survey questions openly and

\section{Results}

Participants generated 80 metaphors under 11 conceptual categories; smart, brain, do not know, nature, security, humanistic, the dilemma of good and evil, service, object, technology, and life and time. The data were collected from participants from both public and private schools. Table 3 shows the difference in frequency of metaphors under the conceptual categories between participants from public and private schools. The categories "humanistic (20)," "brain (13)," and "technology (12)" had the highest number of metaphors.

Table 3. Metaphors and conceptual categories

\begin{tabular}{|c|c|c|c|c|c|c|c|}
\hline \multirow{2}{*}{ Categories } & \multirow{2}{*}{$\begin{array}{l}\text { Number of } \\
\text { Metaphors }\end{array}$} & \multicolumn{2}{|c|}{ Public School } & \multicolumn{2}{|c|}{ Private School } & \multicolumn{2}{|c|}{ Total } \\
\hline & & $\mathrm{f}$ & $\%$ & $\mathrm{f}$ & $\%$ & $\mathrm{f}$ & $\%$ \\
\hline Smart & 5 & 10 & 2.9 & 2 & 1.6 & 12 & 2.5 \\
\hline Brain & 13 & 62 & 17.9 & 15 & 11.7 & 77 & 16.2 \\
\hline Nature & 8 & 13 & 3.7 & 7 & 5.5 & 20 & 4.2 \\
\hline Security & 5 & 6 & 1.7 & 5 & 3.9 & 11 & 2.3 \\
\hline Humanistic & 20 & 108 & 31.1 & 37 & 28.9 & 145 & 30.5 \\
\hline $\begin{array}{l}\text { The Dilemma of Good } \\
\text { and Evil }\end{array}$ & 6 & 15 & 4.3 & 9 & 7.0 & 24 & 5.1 \\
\hline Service & 5 & 10 & 2.9 & 14 & 10.9 & 24 & 5.1 \\
\hline Object & 3 & 2 & 0.6 & 4 & 3.1 & 6 & 1.3 \\
\hline Technology & 12 & 114 & 32.9 & 27 & 21.1 & 141 & 29.7 \\
\hline Life & 2 & 5 & 1.4 & 1 & 0.8 & 6 & 1.3 \\
\hline Time & 1 & 2 & 0.6 & 7 & 5.5 & 9 & 1.9 \\
\hline Total & 80 & 347 & 100 & 128 & 100 & 475 & 100 \\
\hline
\end{tabular}

Participants generated numerous metaphors about AI. The frequency distribution of the metaphors was presented. The most common metaphors were intelligence (20), personality traits (15), human-made (13), source of information (10), beyond human (9), like humans (9), helper (8), imagination (7), computer (7), and danger (6).

This section presented the conceptual categories and metaphors under them. Direct quotations were used to provide an accurate and coherent picture of participants' perceptions of AI.

There were five metaphors under the category "smart" (see Table 4). Most participants emphasized the autonomy of AI. They generally perceived AI as something smart.

Table 4. Direct quotations on the category "smart"

\begin{tabular}{ll}
\hline Metaphor & Direct Quotations \\
\hline Autonomous (5) & $\begin{array}{l}\text { "Some autonomous robots can communicate with the objects around them and collect } \\
\text { information from them and then use their sensors to react to variables, such as sound } \\
\text { and light; so, to me, artificial intelligence is like autonomous." } \\
\text { "They are intelligent and tireless machines like humans." }\end{array}$ \\
Clever Entity (2) & $\begin{array}{l}\text { "You ask something to AI, and it answers, like date, time, it answers any question, } \\
\text { simple or difficult." }\end{array}$ \\
Smart Assistant (2) & "It can use smart and artificial intelligence like a smart human." \\
Smart Human (1) & "The term 'artificial intelligence' speaks for itself; I mean, it's not something natural." \\
\hline
\end{tabular}


There were nine metaphors in four metaphor domains under the category "brain" (see Table 5). Most participants emphasized the intelligence of AI.

Table 5. Direct quotations on the category "brain"

\begin{tabular}{ll}
\hline Metaphor Domain & Direct Quotations \\
\hline Intelligence (25) & $\begin{array}{l}\text { "Artificial intelligence is a highly intelligent brain that performs all types of codes } \\
\text { written into it." } \\
\text { "Artificial intelligence solves every problem and is like a very intelligent human." }\end{array}$ \\
$\begin{array}{l}\text { Source of information } \\
\text { (10) }\end{array}$ & $\begin{array}{l}\text { "Artificial intelligence can reach any information that needs to be reached." } \\
\text { "Artificial intelligence contains a lot of information like a library." } \\
\text { Imagination (7) }\end{array}$ \\
$\begin{array}{l}\text { Artificial intelligence is like a picture because it is the product of a lot of effort, like a } \\
\text { "We can shape and manage artificial intelligence however we want to." } \\
\text { "Everything is connected and follows one another. When we use artificial intelligence, }\end{array}$ \\
Connectedness (4) \\
we need other devices."
\end{tabular}

There were five metaphors in three metaphor domains under the category "nature" (see Table 6). Participants mostly made associations between AI and the earth. They perceived AI as something with no limits.

Table 6. Direct quotations on the category "nature"

\begin{tabular}{ll}
\hline Metaphor Domain & Direct Quotations \\
\hline Earth (8) & "Artificial intelligence knows how Earth and the universe came to be; it can do \\
& $\begin{array}{l}\text { anything." } \\
\text { "The capacity and potential of artificial intelligence are not entirely known; it is } \\
\text { Space (2) }\end{array}$ \\
limitless, like space." & "Artificial intelligence is a very creative and a very nice thing. It is like a very smart \\
Universe (1) & creature that we've created, and it's like a computer made in the image of humans."
\end{tabular}

The category "security" consisted of five metaphors (see Table 7). Participants mostly talked about the potential dangers of AI.

Table 7. Direct quotations on the category "security"

\begin{tabular}{ll}
\hline Metaphor & Direct Quotations \\
\hline & "I think artificial intelligence is a great danger for humans. It may bring the end of \\
humanity." & "Artificial intelligence will rule us in the future. Today, we can keep it under control, \\
but it will develop and bring the end of humanity in the future." & "If robots contract viruses, they may cause unimaginable things in the future" \\
& "They will be the end of us." \\
Threat (3) & "Artificial intelligence is harmful." \\
Harmful (2) & The great states may use artificial intelligence against each other. \\
Weapon (1) & "If we continue to develop AI, it will spread like a virus and eventually take over the \\
Virus (1) & world."
\end{tabular}

There were 16 metaphors in four metaphor domains under the category "humanistic" (see Table 8). Participants focused mostly on the human nature of AI. They associated AI with the human in general. 
Table 8. Direct quotations on the category "humanistic"

\begin{tabular}{ll}
\hline Metaphor Domain & Direct Quotations \\
\hline "Artificial intelligence is like a superman who gives life and brings others back to \\
Personality Traits (15) & $\begin{array}{l}\text { life." } \\
\text { "Artificial intelligence can feel, think, and do things like we do." } \\
\text { "Artificial intelligence is something superior to human intelligence created by human } \\
\text { intelligence." }\end{array}$ \\
Human-made (13) & $\begin{array}{l}\text { Artificial intelligence is like a very smart creature that we've created, and it's like a } \\
\text { computer made in the image of humans. } \\
\text { "The robots have been built by humans, but they have outsmarted humans." }\end{array}$ \\
Beyond human (9) & $\begin{array}{l}\text { "Artificial intelligence is more than just a smart creature." } \\
\text { Like Humans (9) }\end{array}$ \\
\hline
\end{tabular}

There were four metaphors in two metaphor domains under the category "the dilemma of good and evil" (see Table 9). Participants addressed the good and bad sides of AI.

Table 9. Direct quotations on the category "the dilemma of good and evil"

\begin{tabular}{ll}
\hline Metaphor & Direct Quotations \\
& "Life is full of good and evil. Something good will come out of AI if used the right \\
& way, but it will cause evil if used the wrong way. \\
Both good and evil (7) & "Artificial intelligence has bad sides as well as good." \\
& "Artificial intelligence is useful if used in the right way, and harmful if used in the \\
& wrong way." \\
& "Artificial intelligence will be the end of humanity." \\
& "People build robots to get them to do what they do, but one day the robots will take \\
Bad (3) & "Aver the world." \\
& Google gives us information about whatever we search for. Artificial intelligence does \\
Good (2) & not compare to people, I mean, for example, people cannot know everything."
\end{tabular}

There were three metaphors in two metaphor domains under the category "service" (see Table 10). Participants focused on the "assisting" feature of AI.

Table 10. Direct quotations on the category "service"

\begin{tabular}{ll}
\hline Metaphor & Direct Quotations \\
\hline Helper (8) & "Artificial intelligence is there to make our lives easier." \\
Manager (2) & "Artificial intelligence helps us use technology more efficiently." \\
Employee (1) & "Ahe Lion is the king of the forest." \\
\hline
\end{tabular}

The category "object" consisted of three metaphors (see Table 11).

Table 11. Direct quotations on the category "object"

\begin{tabular}{ll}
\hline Metaphor & Direct Quotations \\
\hline Money (1) & "Artificial intelligence allows us to reach information in a highly convenient manner." \\
Knife (1) & "Artificial intelligence is useful if used the right way, and harmful if used the wrong \\
& way." \\
Some autonomous robots can communicate with the objects around them and collect \\
information from them, and then use their sensors to react to variables, such as sound \\
and light; so, to me, artificial intelligence is like autonomous.
\end{tabular}

There were nine metaphors in three metaphor domains under the category "technology" (see Table 12). Participants focused on the "technological" aspect of AI. They saw AI the same as 
some technologies.

Table 12. Direct quotations on the category "technology"

\begin{tabular}{|c|c|c|}
\hline Metaphor & & Direct Quotations \\
\hline Robot (41) & & $\begin{array}{l}\text { "Computers and computer-controlled robots performing various tasks" } \\
\text { "They put something that knows everything in robots, and those robots know } \\
\text { everything and become smarter than people." }\end{array}$ \\
\hline Computer (7) & & "Artificial intelligence performs many tasks like computers do." \\
\hline System (4) & & $\begin{array}{l}\text { "Artificial intelligence is a soft-wired information system ..." } \\
\text { "An operating system used in the field of technology..." }\end{array}$ \\
\hline Boat (2) & & $\begin{array}{l}\text { "Artificial intelligence executes commands in coded software. It's smart, and } \\
\text { especially video game characters called artificial intelligence..." }\end{array}$ \\
\hline Internet (2) & & "Artificial intelligence means the Internet." \\
\hline Phone (2) & & $\begin{array}{l}\text { "The phone means a lot to me. I can reach anything anytime. Artificial intelligence is } \\
\text { positive, and so the phones are smart." }\end{array}$ \\
\hline $\begin{array}{l}\text { Autonomous } \\
\text { (1) }\end{array}$ & Vehicle & $\begin{array}{l}\text { "Artificial intelligence is not operated by people; it is completely based on coding. For } \\
\text { an improvement, when you can't find your car, you press a button on the remote, and } \\
\text { the car drives itself back." }\end{array}$ \\
\hline
\end{tabular}

The category "life" included two metaphors (see Table 13).

Table 13. Direct quotations on the "life" category

\begin{tabular}{ll}
\hline Metaphor & Direct Quotations \\
\hline Childhood (1) & "Artificial intelligence has changed and developed as I have changed and developed \\
& $\begin{array}{l}\text { quite a lot since my childhood." } \\
\text { "Babies are born with a blank slate and learn new things with time. Artificial }\end{array}$ \\
Newborn (1) & $\begin{array}{l}\text { intelligence is the same; if we encode an object to it, it will recognize what that object } \\
\text { is." }\end{array}$
\end{tabular}

The category "time" had only one metaphor (see Table 14).

Table 14. Direct quotations on the category "time"

\begin{tabular}{ll}
\hline Metaphor & Direct Quotations \\
\hline & "I feel like I'm in the future when I see something done with artificial intelligence." \\
Future (5) & "Artificial intelligence develops the way we want it to, just like the way we shape our \\
& future on the path we want it to go." \\
\hline
\end{tabular}

\section{Discussion}

AI, which was initially a part of computer science, has become a promising technology for solving problems in many areas. AI has become an indispensable part of modern life with many products capable of solving problems, and therefore, it is evident that people will use such products more and more in the future, resulting in new lines of business. In this context, AI will have significant impacts on future generations.

AI technology plays an increasingly important role in our lives, especially in education and work life. States aim to turn their students into citizens who are capable of solving possible future problems. Providing students with information about AI is the first step in turning them into people with high AI literacy (Kandlhofer et al., 2016).

This study focused on secondary school students' perceptions of AI. Participants generated 80 
positive or negative metaphors under 11 conceptual categories; smart, brain, do not know, nature, security, humanistic, the dilemma of good and evil, service, object, technology, and life and time.

Under the category "smart," participants noted that AI was a self-responsive clever entity that assisted people. They thought of robot characters in video games and print and visual media. Although the concepts "smart" and "clever" are different, participants saw an intelligent entity as clever.

Under the category "brain," participants found AI an intelligent, creative, and connected source of information. They thought of AI as a creative and connected technology with unlimited knowledge that could solve any problem. Given that we are in the transition phase between ANI (performing specific tasks) and AGI (performing everyday tasks) in AI technology, participants had high expectations of AI. We still discover the limits of the human brain. Since machines have a higher computing capacity than humans, participants believed that AI would outsmart the human brain and solve all problems. Participants associated AI with the brain, suggesting that they had positive perceptions of AI.

Under the category "nature," participants concentrated on the relationship between AI and the earth, space, and universe. To them, there were no limits to what AI was capable of, indicating that they had great expectations of it.

Under the category "security," participants talked about the potentially dangerous, threatening, and harmful aspects of AI. They also argued that AI was a threat to people as it could spread like a biological virus and take over the world and bring an end to humanity or be used as a weapon by some states. We think that participants have been affected by the news in print and visual media, which talk about AI taking over jobs and evil AI characters in videogames. UNICEF (2020) also reports that privacy concerns are cropping up among children because they think that AI-based algorithms are collecting too much information about them.

Under the category "humanistic," participants saw AI as a human-like technology created by human intelligence but can outsmart humans in some areas. Those who thought of AI as something that could feel and think like humans attributed human characteristics to it. Growing importance of human-like machines may have caused them to think that way (Cath et al., 2018). Although some participants argued that humans had been outsmarted by robots that they had built, robots can outsmart people only in certain tasks and to the extent of their computational capacity. Robots that could perform different types of tasks as well as humans have not yet been built. Some participants stated that AI mimicked human behavior and thoughts. Under the category "human," participants associated AI with positive human traits. However, UNICEF (2020) reports that some children are against the idea of AI replacing human interaction altogether.

Under the category "the dilemma of good and evil," participants addressed both positive and negative aspects of AI. They stated that AI had bad sides as well as good and that its successes depended on how it was used, for good or evil. They thought that AI was not capable of thinking by itself but that it did what humans instructed it to do.

Under the category "service," some participants found AI helpful, while others considered it a threat to employment. Children are also concerned about the possibility of AI taking over jobs 
(UNICEF, 2020). Through decision support systems, AI assists employees in different lines of business (Reference). For example, AI has replaced human employees in banks or supermarkets. On the other hand, AI supports employees in different lines of business and helps them improve themselves. Participants' negative perceptions may be a result of their concern about the possibility of AI taking over jobs.

Under the category "object," participants used such metaphors as money, knife, and glass to describe AI, suggesting that they perceived AI as something tangible.

Under the category "technology," participants regarded AI as an advanced online information system that could perform numerous tasks and operations performed initially by robots and computers. They used the metaphors of "robot," "computer, system," "boat," and "autonomous vehicle" to describe AI, indicating that they had the right information about it. The fact that they associated AI with "robots" suggested that they had positive attitudes towards it. Secondary school students are, in general, for the use of robots in schools (Lee et al., 2008).

Under the category "life," participants used the metaphors of "childhood" and "newborn," associating AI with the early stages of life. With these metaphors, participants meant that they saw AI as a type of technology that was in the early stages of its life and learning new things and improving itself day by day as babies and children did. Under the category "time," participants saw AI as a form of technology from the future because of its amazing features.

\section{Conclusion}

In this study, the perceptions of secondary school students about AI were determined through the use of metaphors. For the participants, AI had both positive and negative connotations. Participants mostly associated AI with humans, technology, and the brain. Participants used positive metaphors to explain AI, demonstrating that they had positive views of AI. This situation is very important, so they must be ready for the future of AIsupported education (Luan et al., 2020). Some of the students had negative connotations, such as danger, threat, virus, and evil, as in some literature studies (UNICEF, 2020). Among the positive aspects of AI technology, there are still points that students are worried about. This research has ability to influence the understanding and design of students' expectations of the design or use of educational computer systems by developers. Educational computer systems can be designed to shape students' perceptions of AI. Teachers can consider students' perceptions of AI by using AI-assisted teaching and designing content to enhance students' learning skills. Student perceptions found within the scope of this study can be a reference for teachers at this point (Song \& Wang, 2020). Students should be taught not only AI technologies, but also the concepts and skills that made them possible (Yu \& Chen, 2018). Future research can perform semi-structured interviews with secondary school students to assess what they think about AI. This research can be replicated with high school and university students to explore their impressions of AI.

\section{Limitations}

There were several limitations. First of all, the study was limited to the central districts of Afyonkarahisar and Izmir. The results were limited to seventh and eighth graders. The results were based on self-report. Due to the nature of qualitative research, generalizability of this research seems limited. However, findings may resonate in similar research settings (Kuper, et al., 2008; Twining et al., 2017). 


\section{References}

Akay, C. (2017). Turkish High School Students' English Demotivation and Their Seeking for Remotivation: A Mixed Method Research. English Language Teaching, 10(8), 107122.

Arauja, T., Helberger, N., Kruikemeier, S. \& Vreese, C.H. (2020). In AI we trust? Perceptions about automated decision-making by artificial intelligence. AI \& Society, 35: 611-623.

Avidov-Ungar, O., Shamir-Inbal, T., \& Blau, I. (2020). Typology of digital leadership roles tasked with integrating new technologies into teaching: Insights from metaphor analysis. Journal of Research on Technology in Education, 1-16.

Bostrom, N. (2003). Ethical issues in advanced artificial intelligence. Science Fiction and Philosophy: From Time Travel to Superintelligence, 277-284.

Bostrom, N. \& Yudkowsky, E. (2014). The ethics of artificial intelligence. In K. Frankish \& W. Ramsey (Eds.), The Cambridge Handbook of Artificial Intelligence (pp. 316-334). Cambridge: Cambridge University Press. doi:10.1017/CBO9781139046855.020.

Bösch, P. M., Becker, F., Becker, H. \& Axhausen, K. W. (2018). Cost-based analysis of autonomous mobility services. Transport Policy, 64, 76-91.

Cath, C., Wachter, S., Mittelstadt, B., Taddeo, M., \& Floridi, L. (2018). Artificial intelligence and the 'good society': The US, EU, and UK approach. Science and Engineering Ethics, 24(2), 505-528

Cellan-Jones, R. (2014, December 2). Stephen Hawking warns artificial intelligence could end mankind, BBC. Retrieved 15.10.2020 from https://www.bbc.com/news/technology-30290540

Chai, C. S., Lin, P. Y., Jong, M. S. Y., Dai, Y., Chiu, T. K., \& Qin, J. (2021). Perceptions of and behavioral intentions towards learning artificial intelligence in primary school students. Educational Technology \& Society, 24(3), 89-101.

Chassignol, M., Khoroshavin, A., Klimova, A. \& Bilyatdinova, A. (2018). Artificial Intelligence trends in education: a narrative overview. Procedia Computer Science, $136,16-24$.

Clarke, R. (2019). Why the world wants controls over Artificial Intelligence. Computer Law \& Security Review.

Cross, A. \& Lucas, E. (2019). Getting into Medical School 2020 Entry. Trotman Education.

Dai, Y., Chai, C. S., Lin, P. Y., Jong, M. S. Y., Guo, Y., \& Qin, J. (2020). Promoting students' well-being by developing their readiness for the artificial intelligence age. Sustainability, 12(16), 6597.

Dickson, B. (2017, May 12). What is Narrow, General and Super Artificial Intelligence. TechTalks. Retrieved 15.10.2020 from https://bdtechtalks.com/2017/05/12/what-isnarrow-general-and-super-artificial-intelligence

Dubhashi, D. \& Lappin, S. (2017). AI dangers: Imagined and real. Communications of the ACM, 60(2), 43-45.

Elahi, E., Weijun, C., Zhang, H. \& Nazeer, M. (2019). Agricultural intensification and damages to human health in relation to agrochemicals: Application of artificial intelligence. Land Use Policy, 83, 461-474.

Gelmereanu, C., Morar, L. \& Bogdan, S. (2014). Productivity and cycle time prediction using artificial neural network. Procedia Economics and Finance, 15, 1563-1569.

Hajian, S., Bonchi, F., \& Castillo, C. (2016). Algorithmic bias: from discrimination discovery to fairness-aware data mining. In: Proceedings of the 22nd ACM SIGKDD International Conference on Knowledge Discovery and Data Mining - KDD'16. ACM Press, San Francisco, California, USA, pp 2125-2126. https:// doi.org/10.1145/2939672.2945386. 
Kim, J., Merrill, K., Xu, K., \& Sellnow, D. D. (2020). My teacher is a machine: Understanding students' perceptions of AI teaching assistants in online education. International Journal of Human-Computer Interaction, 36(20), 1902-1911.

Köse, U. (2018), Are We Safe Enough in the Future of Artificial Intelligence? A Discussion on Machine Ethics and Artificial Intelligence Safety. Broad Research in Artificial Intelligence and Neuroscience, 9 (2), 184-197.

Kandlhofer, M., Steinbauer, G., Hirschmugl-Gaisch, S. \& Huber, P. (2016, October). Artificial intelligence and computer science in education: From kindergarten to university. In 2016 IEEE Frontiers in Education Conference (FIE) (pp. 1-9). IEEE.

Kuper, A., Lingard, L., \& Levinson, W. (2008). Critically appraising qualitative research. BMJ, 337,a1035. https://doi.org/10.1136/bmj.a1035

Lee, E., Lee, Y., Kye, B. \& Ko, B. (2008, June). Elementary and middle school teachers', students' and parents' perception of robot-aided education in Korea. In EdMedia+ Innovate Learning (pp. 175-183). Association for the Advancement of Computing in Education (AACE).

Lincoln, Y.S., \& Guba, E.G. (1985) Naturalistic Inquiry. Newbury Park, CA: Sage Publications.

Luan, H., Geczy, P., Lai, H., Gobert, J., Yang, S. J., Ogata, H., Baltes, J., Guerra, R., Li, P., \& Tsai, C. C. (2020). Challenges and future directions of Big Data and Artificial Intelligence in education. Frontiers in Psychology, 11.

Matua, G. A., \& Van Der Wal, D. M. (2015). Differentiating between descriptive and interpretive phenomenological research approaches. Nurse Researcher, 22(6).

McCarthy, J., Minsky, M. L., Rochester, N. \& Shannon, C. E. (2006). A proposal for the dartmouth summer research project on artificial intelligence, august 31, 1955. AI Magazine, 27(4), 12-12.

Miles, M. B. \& Huberman, A. M. (1994). Qualitative data analysis (Thousand Oaks, CA: Sage).

Nowak, A., Lukowicz, P. and Horodecki, P. (2018). Assessing Artificial Intelligence for Humanity: Will AI be the Our Biggest Ever Advance? or the Biggest Threat [Opinion], in IEEE Technology and Society Magazine, vol. 37, no. 4, pp. 26-34, Dec. 2018, doi: 10.1109/MTS.2018.2876105.

O'Brien, B. C., Harris, I. B., Beckman, T. J., Reed, D. A., \& Cook, D. A. (2014). Standards for reporting qualitative research: A synthesis of recommendations. Academic Medicine, 89(9), 1245e1251. https://doi.org/10.1097/ACM.0000000000000388.

Pujilestari, S., Sayuti, M., \& Tentama, F. (2021). The Influence of Parental Guidance, Group of Peers, School Promotion, and Career Information on Course Preference Decision Class X SMK Muhammadiyah in Bantul. Journal of Vocational Education Studies, 4(1), 11-27.

Saban, A. (2008a). Primary school teachers' and their students' mental images about the concept of knowledge. Elementary Education Online, 7(2), 421-455.

Saban, A. (2008b). Metaphors about school. Educational Administration - Theory and Practice, 14(3), 459-496.

Santiago-Delefosse, M., Gavin, A., Bruchez, C., Roux, P., \& Stephen, S. L. (2016). Quality of qualitative research in the health sciences: Analysis of the common criteria present in 58 assessment guidelines by expert users. Social Science \& Medicine, 148,142e151. https://doi.org/10.1016/j.socscimed.2015.11.007.

Singh, G., Mishra, A., Sagar, D. (2013). An overview of artificial intelligence. SBIT Journal of Science and Technology. 2(1). 10.13140/RG.2.2.20660.19840.

Sinha, S. (2018, May 8) "China Publishes First AI Textbook to Educate High School Students" Analytics India. Retrieved 15.10.2020 from 
www.analyticsindiamag.com/china-publishes-first-ai-textbook-to-educate-highschool-students/

Sit, C., Srinivasan, R., Amlani, A., Muthuswamy, K., Azam, A., Monzon, L., \& Poon, D. S. (2020). Attitudes and perceptions of UK medical students towards artificial intelligence and radiology: a multicentre survey. Insights into imaging, 11(1), 1-6

Sitterding, M. C., Raab, D. L., Saupe, J. L. \& Israel, K. J. (2019). Using artificial intelligence and gaming to improve new nurse transition. Nurse Leader, 17(2), 125-130.

Skilton, M. \& Hovsepian, F. (2017). The 4th Industrial Revolution: Responding to the Impact of Artificial Intelligence on Business. Springer.

Song, P., \& Wang, X. (2020). A bibliometric analysis of worldwide educational artificial intelligence research development in recent twenty years. Asia Pacific Education Review, 21(3), 473-486.

Tavana, M., Abtahi, A. R., Di Caprio, D. \& Poortarigh, M. (2018). An artificial neural network and bayesian network model for liquidity risk assessment in banking. Neurocomputing, 275, 2525-2554.

Teksan, K. (2019). The perceptions of students studying in the faculty of education towards reading in terms of their reading motivations. International Journal of Progressive Education, 15(5), 162-184.

Touger, G. E. (2018, August 3) "What's the Difference between Artificial Learning (AI), Machine Learning, and Deep Learning?" Prowesscorp. Retrieved 15.10.2020 from www.prowesscorp.com/whats-the-difference-between-artificial-intelligence-aimachine-learning-and-deep-learning

Twining, P., Heller, R. S., Nussbaum, M., \& Tsai, C. C. (2017). Some guidance on conducting and reporting qualitative studies. Computers and Education, 106, A1-A9.

United Nations Children's Fund (UNICEF). (September, 2020). Policy guidance on AI for children Policy guidance on AI for children. Retrieved 15.10.2020 from https://www.unicef.org/globalinsight/media/1171/file/UNICEF-Global-Insight-policyguidance-AI-children-draft-1.0-2020.pdf

World Bank. (2018). Better Data for Doing Good: Responsible Use of Big Data and Artificial Intelligence. In Information and Communications for Development. Information and Communications for Development 2018: Data-Driven Development (pp. 33-50). https://doi.org/doi:10.1596/978-1-4648-1325-2_ch3

Yıldırım, A. \& Şimşek, H. (2011). Qualitative research methods. (8th Edition). Ankara: Seçkin Publishing.

Yu, Y. \& Chen, Y. (2018). Design and development of high school artificial intelligence textbook based on computational thinking. Open Access Library Journal, 5(9), 1-15.

Yun, D., Xiang, Y., Liu, Z., Lin, D., Zhao, L., Guo, C., ... \& Wu, X. (2020). Attitudes towards medical artificial intelligence talent cultivation: an online survey study. Annals of Translational Medicine, 8(11).

Yüzbaşığlu, E. (2021). Attitudes and perceptions of dental students towards artificial intelligence. Journal of Dental Education, 85(1), 60-68.

Zinan, C. \& Kai, G. (2018, November 22). "AI textbooks for Chinese kindergarteners released" China Daily. Retrieved 15.10 .2020 from http://www.chinadaily.com.cn/a/201811/22/WS5bf66272a310eff30328a73a.html 